\title{
RISK ENVIRONMENT AS SOCIAL REALITY CHANGE FACTOR: THE PROBLEM OF SOCIAL REGULATION
}

1) Doctor of Social Sciences, Professor, the head of Sociology of Youth department. Institute of Socio-Political Research, RAS. Fotiyevoy str., 6, bl. 1, Moscow, 119333, Russia. E-mail: uzubok@mail.ru 2) Doctor of Social Sciences, Professor, Chief Researcher. Institute of Socio-Political Research, RAS Fotiyevoy str., 6, bl. 1, Moscow, 119333, Russia. E-mail: chuprov443@yandex.ru

\begin{abstract}
The article explains the theoretical concept of modern environment study transformation based on risk approach. The risks occurring in the environment are conceptualized as the environmental and the activity phenomenon appearing during the transition from certainty to uncertainty and vice versa. The dialectical relationship of uncertainty and non-linearity is argued in changing social reality of modern risk society. The problems of risk social regulation in a changing reality.

Reflecting in the construction of own social reality by people, in the formation of ideas about it, the risks are mediated by the subjective interpretation of environmental conditions and are manifested in the interpretation of its phenomena, endowed with subjective senses, and in activity motivation during the interaction with risk environment. Risk environment as the changing social reality is only partly the determination of objective reality, but mostly becomes a culturally constructed phenomenon, the product of human relationships. Phenomenological paradigm acts as the theoretical and methodological source of its justification.

The change in the mechanism of social regulation within the new social reality, the weakening of its institutional aspects and strengthening of self-regulation aspects is substantiated. The processes of symbolization, simulation and performance are revealed in the risk self-regulation.

Keywords: risk; risk environment; uncertainty; non-linearity; changing social reality; social regulation and the self-regulation of risk.

Acknowledgement: The study was supported by the grants of Russian Science Fund, the project №14-38-00047 «Prediction and management of social risks concerning the development of anthropogenic systems in the dynamics of human environment transformation processes».
\end{abstract}

Зубок Ю.А. ${ }^{1}$

Чупров В. И. ${ }^{2}$

\section{РИСКОГЕННОСТЬ СРЕДЫ ОБИТАНИЯ КАК ФАКТОР ИЗМЕНЕНИЯ СОЦИАЛЬНОЙ РЕАЛЬНОСТИ: ПРОБЛЕМА СОЦИАЛЬНОЙ РЕГУЛЯЦИИ}

1) доктор социологических наук, профессор, заведующая отделом социологии молодежи. Институт социально-политических исследований РАН,

ул. Фотиевой, д. 6, к. 1, Москва, 119333, Россия. Электронный адрес: uzubok@ mail.ru

2) доктор социологических наук, профессор, главный научный сотрудник. Институт социальнополитических исследований РАН,

ул. Фотиевой, д. 6, к. 1, Москва, 119333, Россия. Электронный адрес: chuprov443@ yandex.ru

Аннотация. В статье обосновывается теоретическая концепция исследования трансформации современной среды обитания на основе рискологического подхода. Риски, возникающие в среде обитания, концептуализируются как явления средового и деятельностного характера, возникающие в процессе перехода от определенности к неопределенности и наоборот. Аргументируется диалектическая связь неопределенности и нелинейности в изменяющейся социальной реальности современного общества риска. Проблемы социальной регуляции риска в условиях изменяющейся реальности.

Отражаясь в конструировании людьми собственной социальной реальности, в формировании представлений о ней, риски опосредуются субъективной интерпретацией средовых условий и проявляются, в истолковании ее феноменов, наделенных субъективными смыслами, и проявляются в мотивации деятельности в процессе взаимодействия с рискогенной средой. Рискогенная среда как изменяющаяся социальная 
реальность лишь отчасти является детерминацией объективной действительности, но преимущественно становится культурно сконструированным феноменом, продуктом человеческих отношений. Теоретико-методологическим источником ее обоснования выступает феноменологическая парадигма.

Обосновывается изменение механизма социальной регуляции в условиях новой социальной реальности, ослабление институциональных его аспектов и усиление саморегуляционных. В саморегуляции риска выделяются процессы символизация, имитации и перфоманс.

Ключевые слова: риск; рискогенная среда обитания; неопределенность; нелинейность; изменяющаяся социальная реальность; социальная регуляция и саморегуляция риска.

Благодарность: Исследование выполнено при поддержке гранта Российского научного фонда, проект №14-38-00047»Прогнозирование и управление социальными рисками развития техногенных человекомерных систем в динамике процессов трансформации среды обитания человека».

The risks occurring in the global environment are manifested uniquely and influence the life activity of individuals and groups. They are reflected in the construction of own social reality by people - in the development of perceptions about it mediated by a subjective interpretation, in the interpretation of its phenomena, endowed with subjective senses, and are manifested in the conscious intent and the motivation of activity during the interaction with risk environment. The changing social reality is only partly the determination of objective reality, but it becomes mostly a culturally constructed phenomenon, the product of human interaction.

A number of new social risk related problems appears due to the interaction of individuals and groups with risk environment. They are the social consequences of the threats caused by the violation of the natural-environmental, anthropogenic, information and socio-cultural security. The features of these threats overcoming in a changing social reality actualize the problem of risk social regulation.

\section{Risks in modern global environment}

An objective prerequisite of risk in modern society is an innovative component of its dynamic development, which changes a person and his environment.

Understood in broad terms as the environment, the conditions of human existence, the habitat is divided into natural and artificial one. The first one is the set of all natural and social conditions of a particular place of his residence, while the second one is a man-made material world, forming a sociocultural, technological, informational and economic infrastructure (subenvironmental $\operatorname{loci}^{1}$ ). The uncontrolled consequences of these conditions

\footnotetext{
${ }^{1}$ Locus is understood as a place in the human environment, defining the features of his life activity conditions associated with specific natural, technological, social and cultural environment.
}

change and development contribute to the increase of uncertainty and the emergence of risks.

The variety of habitat arising risks includes the risks of ecological (environmental) disaster caused by human intervention in nature; all kinds of risks associated with the negative effects of scientific and technological development, as well as with the development of global information systems; the risks resulting from the alteration and destruction of the social and cultural human environment and his everyday practices; the risks appearing in commercial, industrial and economic activity ${ }^{2}$. "They are the product of advanced industrial technology and they will be continuously strengthened with their further improvement» [1, p. 24]. According to U. Beck, the systematic human vulnerability to threats caused by modernization itself, produces an innovative risk which becomes a systematic and complex one in modern rapidly changing society. The production of wealth in it prevails in comparison with the production risk and the benefits of technical and economic progress is pushed increasingly into background by the the production of risks [1, p. 14].

The constructive, technical, technological imperfections, the errors during their operation, the limited knowledge about potential threats and their neglect because of commercial interests, the noncompliance with the technological discipline and the violation of safety regulations, the negligence and carelessness in present conditions increases the severity of a mistake and the burden of social

\footnotetext{
${ }^{2}$ See: Beck U. Risk society. On the way to another modernist style. M., 2000; Giddens E. Elements of structuration theory // Modern social theory: Bourdieu, Giddens, Habermas. Textbook. Novosibirsk, 1995; Yanitsky O.N. Sociology of risk. M., 1998; Mozgovaya A.V. Sociology of risk: the possibility of theoretical and empirical knowledge synthesis // The risk phenomenon in social space / Chief editor A.V. Mozgovaya. M., 2001; V.I Chuprov, Zubok Y.A., Williams K. Youth in risk society. M., 2003; Zubok Y.A. The phenomenon of risk in sociology: Youth study experience. M., 2007; Yakovenko I.G. The risks of Russian society social transformation: culturological aspect. M., 2006.
} 
consequences immensely within the complex of subenvironmental technological loci. In this regard, L.G. Ionin wrote: «The incredible complexity of the technological, economic and social systems in the process of their permanent partial improvement and upgrade led gradually to the fact that they become incomprehensible and uncontrollable on the part of their creators and develop their own, unplanned and uncontrolled ways of working. This explains the plurality of so-called man-made disasters, this explains the failures of political democracy, providing power to authoritarian leaders, that this, finally, due to the economic crises that people learn to predict on the basis of «circular process», «big waves» theory, etc., taking paradoxical attempts to expose to an objective analysis the things they invented and created themselves. Pure and simple this means the aquisition of its own organic or quasiorganic life by technical, economic and other systems ...» [2, p. 143]. In these circumstances «serious incidents are unavoidable even with the best management, and full attention to safety» [3], causing the so-called «normal accidents».

The accidents at nuclear power plants, transport and space disasters, the explosions of gas pipelines, the danger of new biotechnology use in medicine and food industries proves the ambivalence of innovations that provide a modern man an opportunity to enjoy the scientific and technical achievements, and at the same time increase the likelihood of accidents and destructive effects on himself and its habitat. And the concentration of hazardous materials and the population in such hazardous areas makes the consequences of natural and industrial / technological disasters even more dramatic [4].

The qualitative changes of the environment are associated with the transformation of subenvironmental loci, the emergence of the global threat to a human life on the planet, provide a clear man-made sense to a risk and bring to the agenda the issue of human survival within the rising wave of environmental threats. The problem of global warming and flooding of entire regions of the world, the change of biological balance in the environment and the deterioration of biological resources entail the deterioration of life quality and conditions, causing poverty and forced migration, introducing uncertainty and risk to the vital activities of different communities around the world.

Due to the spread of information technologies, the process of reality virtualization, the development of an imaginary, artificial world of signs and symbols become important sign of the modern environment transformation. Real relations are superseded with simulacra - signs or images without the meaning of the specific objects, phenomena, events and acting as falsifications of an original thing [5, p. 568-570]. They are perceived by people due to the associations with specific objects and acquire autonomous meaning.

The development of information technologies as a separate cluster of technological advances allows to perform a manipulative influence on mass consciousness [6]. The manipulation is based on the substitution or on artificial belittling or exaggerating of some social needs, ideals and actions. In contrast to the propaganda, manipulation restricts one's consciousness. Manipulation introduces unambiguous patterns designed to change the behavior of communities for the benefit of other persons, social groups, institutions, state and public structures. The manipulative techniques are one of virtualization factors.

The changes typical for the era of postmodernism are related to the acceleration observed in all spheres of modern society activities. They are manifested in the growing dynamism of social interactions, in a rapid birth and fast withering of new social formations in the expansion of individual and group freedom, in the reduction of changing life situation predictability. They are characterized by «the reduction of the present - the process of time interval shortening where you may be sure in certain constancy of our vital relationship» [7, p. 94].

This directly influences the socio-cultural sphere as a subenvironmental locus and is expressed in the transformation of value, standard and moral grounds of activities. Blurred and uncertain, and thus flimsy and fragile new cultural assumptions are not unambiguous by their nature and may be violated without special effects. Creating the sense of pluralism, democracy and tolerance, they are not able to ensure the predictability of social relations.

The collapse of the value-regulatory models and the weakening of social control become the cause of normativity destruction. An anomic state as the result of normativity destruction, once being E. Durkheim analysis subject in the context of culture disorganization and the dysfunctionality of values, $R$. Merton analysis in terms of institutional dysfunctions and socially significant differences of values and the means of their achievement, as well as Erich Fromm analysis, from the perspective of human destructiveness production [8] becomes an immanent state of modern society that promotes the growth of social uncertainty and an increased risk. Since unambiguous standards are subject to atrophy, they are changed by particularism, instantaneousness, an accident, where the truth is mixed with falsehood and 
is inseparable from it as well as the virtue from vice, and the nobility from meanness and the promises become not obligatory; explanations do not find out anything, the expressed opinions are not based on convictions.

The refusal from absolute values and the transition to temporary contractual arrangements creates a situation where each develops his own system of values, which is convenient for his comfortable life. It is characterized by fragmentation, according to T. Luqman definition, «the lack of general knowledge about the due one, that is the morality comprehensive and shared by all». Since the uniquely shared understanding of the permissible and impermissible disappear, the concern that certain behavior will be followed by complications in career, or relationships with others is weakened considerably. Moral regulators lose their stability, people, including decision makers that influence the lives and welfare of others, become «morally ambivalent» and their moral actions are rather random ones [9]. Diversity, duality, the relativity of value, norms and moral criteria remove the last restrictions on the production risks. Thus, universal and specific values are inferior before the onslaught of personal needs and commercial interests of individuals and corporations in the socio-cultural sphere.

At that the only certainty in the sociocultural locus is in the fact that the vector of «time arrow» is irrevocably directed towards increasing complexity, increasing change and constant restructuring of a man's life environmental conditions, as well as the entire system of social connections and relationships, i.e. towards the complete and absolute «end of certainty» [10]. And the destruction of standardization in this context acts as an objective process, the part of «normal anomie» development, reflecting the form of a complex society existence. [11]. S.A. Kravchenko describes normal anomie as «the expansion of aggregate vulnerabilities for society as the side effects of innovative, rational and pragmatic activity of a man». Its essence and accompanying risks developing new vulnerabilities for society are marked by constant update of social and cultural patterns, pluralism of standards and the admissibility of its configurations; «temporal timezone disease» as well as the coexistence of different «tempoworlds» when the regulatory representations of different groups are related to different types of social time and are opposed together to «institutionalized cosmopolitanism» (U. Beck term), reproducing and distributing the so-called global norms as the universal phenomena of modern culture; virtual reality with its simulative practices, performances and the inevitable blurring of edges between the real and imaginary; multiparadigmatic character, at which none is true one in the classic sense, but each represents only the part of reality, and together they give a more or less complete representation about it, the combination of knowledge and ignorance which is the basis for the choice. On this basis, the criterion base of risk assessment significantly eroded, and natural or «normal anomie» as an objective result of the normativity destruction concerning a modern complicated society creates the situation of blurry, hazy, ambiguous, incomplete and the absence of structuring that can not be covered with a single system of description (the Heisenberg principle). On the basis of modern ideas about society, permanently losing certainty, there are some reasons to talk about the absence of structuring as the form of social and cultural locus functioning and the determination of new forms of risk.

Thus, the risks that make the part of modern global environment, reflect the negative effects of a modern man natural interaction with complex technical and technological systems, periodically providing «standard» failures, and define the state and trends of objective reality by the reformatting of axiological structures.

At that the condition of its occurrence is the transition from certainty to uncertainty, or vice versa. In the transition state the signs of certainty necessary for the selection of alternative actions still exist, while in the terms of complete uncertainty the possibility of a purposeful choice is absent. An important base in the sociological understanding of a risk was the extraction of its two forms environmentsl risk as the life activity condition (an objective one) and activity risk (a subjective one). Based on this risk is defined as the characteristic of activity or environmental conditions of a peson's life, group, society during the transition from the state of certainty to the state of uncertainty, and vice versa, when there is a reasonable possibility of choice when the likelihood of a presumed result achievement, a failure or the deviation from a target is assessed, taking into account the moral and ethical norms ${ }^{1}$. Environmental risks reflecting during the construction of social reality, take the form of activity-related risks. In its turn, the escalation of activity-related risks within the conditions of growing uncertainty becomes a determinant of all its new

\footnotetext{
See in details: V.I. Chuprov, Zubok Yu.A., Williams K. Youth in risk society. 2nd ed. M., 2003, p. 41; Zubok Y.A. The problem of risk in the sociology of youth. M., 2003, p. 122; Zubok Y.A. The phenomenon of risk in sociology: Youth study experience. M., 2007, pp. 136-137.
} 
phases. And they risks become the factor of social reality change.

The dialectics of uncertainty and nonlinearity in the changing social reality of modern risk society

An uncontrolled change of natural, technological, information, socio-cultural systems is reflected in the change of social reality (environment) as the uncertainty and non-linearity of its changes. In a broad sense, indefinite, indistinct or not fully cognized processes and phenomena, unclear, vague ideas about the existence, the evasive judgments or behavior of individuals and groups are considered as not definite ones.

The uncertainty in modern society is the result of its acceleration, the collapse of stable social structures and relationships, the blurring of their contours and shapes, is realized in the unstructured environment, the blurring of boundaries between its properties and states of its subenvironmental loci when it is impossible to comprehend whether risk is its inherent characteristic, or a short-term condition.

Social uncertainty stems from the infinite public relations that are constantly going through the stages of formation and decay. It is associated with the emergence of new structures and norms, new nuances of relationships and is the prerequisite for social development. The variety of social relationships, interactions and emerging alternatives is a necessary source of possibility selection. The variety of possibilities transformed into a result, becomes a certainty in its turn. Ultimately, the transformation of uncertainty in certainty actually means the turning of many possibilities into reality. The transition of the social system from one state to another is accomplished by selection of the most effective ones in a certain situation from the plurality of possible ones. At that, the certainty in the development process characterizes a tough, unambiguous relation and an uncertainty characterizes a many-valued relation. In a state of uncertainty the necessity is expressed via the uniqueness of opportunity transition into reality. For the uncertainty the manifestation of the need is not as an inevitable thing, but as an opportunity and a chance. In the broadest sense the phenomena that may be or may not be are called random ones. In the most general form of an accident is «such type of communication, which is conditioned by irrelevant, external attendant causes for this phenomenon» [12, p. 207]. That is a casual type of communication is not determined by a phenomenon, but is brought in from outside. The randomness perceived as a subjectively unexpected, has an unpredictable, unstable character. In such random phenomena the uncertainty is manifested fully and becomes a nonlinearity factor.
Non-linearity understood as indeterminacy, openness and an accident implies the absence of direct forms of relationship between different variables, that is, a change of one does not necessarily entail the change of the other. Nonlinearity causes the unpredictability, irrationality, involuntariness in the course of social development. According to S.A. Kravchenko, it is caused by «the transition of a new threshold of dynamic complexity by a significant part of modern society, which resulted in a global local diversity permeated by disordered vibrations» $[5$, p. 23]. In other words, it is conditioned by the result of uncertainty.

Nonlinear developing conditions are characterized by «wave, oscillatory processes of fight, competition and alternate victories of two dialectically opposed trends - the sustainability of relations in this system and the instability of fluctuations introduced from the outside and shaking the structure from within» $[13$, p. 54]. Then, nonlinearity becomes the form of uncertainty, and the system acquires a nonlinear character of development. However, the non-linearity may strengthen the possibility of positive social change, and intensify dramatically the absence of structural connections within a system. Thus, it becomes the factor of uncertainty growth, i.e. it becomes the cause of uncertainty from its result. Accordingly, it ceases to be a form of uncertainty and it becomes its condition.

«The non-linearity of social evolution is not an infinite multiplicity of historical opportunities during the bifurcation period, but a certain social dilemma, since the choice is made by cognitive subjects capable to understand and assess the impact of society differentiation with respect to a limited number of future societal attractors» [13, pp. 36-37]. As the result, the creation of non-linear emerging media, organizes multi-directional actions of social actors, realizes their potential for self-organization, becoming the social order factor of postmodern type, defined by I. Prigozhin and I. Stengers as the order generated out of chaos [14, p. 96-115].

In comparison with the Heisenberg «uncertainty principle», an unfinished state and incompleteness mean that "one and the same event, the same reality may be covered ... by the two opposing ways of description, the reality acquires the features of uncertainty, i.e. the combination of two (or more) opposite opportunities» $[15$, p. 81$]$. If «it is possible to determine the degree of an option probability qualitatively and quantitatively» the individual risk situations appear [16, p. 19]. But the presence of opposite opportunities creates the situations with many unknown variables that do not have a clear outcome and making people or the system as a whole 
to have an inevitable choice - a necessary risk act. Consequently, risk is an activity mechanism removing the uncertainty through the practical transformation of capabilities into reality within multi-variant terms.

However, uncertainty is manifested not only in the combination of several opposite features, but in the absence of clearly defined relationship between the events and their consequences, which makes the relation between an action and a result a non-linear, i.e. an ambiguous one. Therefore, the risk of activity does not become a calculated one within the extent where he is able to give a secured result, but creates a new uncertainty, provoking the talks about the incompetence of decision-makers and an unjustified risk [17, p. 68]. From this viewpoint, any administrative intervention consisting in the choice of the means and methods of ordering within the system embodying an activity risk may provide the result opposite to an expected one, i.e. to provoke a new uncertainty instead of achieving a certainty.

This is the mechanism of formation of a modern «risk society» development. The following factors became the determinants of the intrusion in its backbone elements and in its social nature: radicalism and the relative speed of change; the absence of clearly progressive, and most importantly, the positive direction of change; the duration and the depth of anomie caused by an advance decomposition of old social institutions compared with the creation of new ones; principal relationship of progress and results with the subjective factors which are almost equal to objective ones by importance (or, let's say, are objectified in the process), including the behavior of the ruling elite and the groups of influence; a weak controllability and predictability of a process; a significant share of natural elements of development and its unclear results [18, c. 133; 19, pp. 42-43]. These processes are vividly manifested in the Russian society. And the risk became an immanent part of individual and group interaction with the environment.

The specified processes are intensified by periodically occurring crisis at the absence of sustainable mechanisms of its regulation, when the discontinuity of social and cultural environment existence is associated with the reproduced sudden and dramatic changes - the crisis - in each of its main segments (loci). The crisis becomes the cause of a risk acquiring a systemic character. Appearing uniquely in each complex subenvironmental loci, a risk influences the fundamental mechanisms of social reproduction. O.N. Yanitsky writes: «In such a society the key natural conditions to ensure a human activity (water, air, soil, food), as well as socio-technical life-support systems developed by him (urban environment, energy and transport systems), turn into the sources of risk. Thus, the life support medium is transformed into a life destruction environment», it experiences an «organic violation in the production system of resources required for the normal functioning of society .... It only degrades, turning into a pile of protective systems «[20, p. 26, 31].

Since «natural and social environments are not limited to the role of risk accumulation and become their producers» $[20$, p. 26], this changes the nature of public relations, interactions and relations of social reproduction as a whole. Thus, risk society is a particular way of social relations, interactions and relationship development between people who are in a transition state from certainty to uncertainty (or vice versa) when the reproduction of the life means (living conditions), physical and spiritual powers of an individual is mostly casual and spontaneous displacing by the risk production [21, pp. 162-163].

Thus, the risk on the one hand, becomes the property of individual environment objective reality, and on the other hand, it is manifested in their individual unpreparedness and the inability to operate in such conditions, the inability to optimize its possible consequences.

\section{Problems of risk social regulation in a changing reality}

The special report of the British Royal Society states that the fact of an objective risk existence is questioned by individuals in more or less subjective manner [22]. On this basis, risk is considered as a constant value, while the response of people on its occurrence is interpreted as a dependent variable. Therefore, the problem of risk management is updated when risk itself is seen as a social reality phenomenon.

A man perceives directly the part of an objective reality, about which he has his own knowledge. The knowledge and experience obtained during intersubjective interactions is objectified and transformed into an image that corresponds to some object. And the object becomes a known, familiar and real one. Therefore, «social reality» is understood as «the entire set of objects and events in the sociocultural world as the object of everyday consciousness of people living their daily lives among similar ones and related to them with various interaction relations» [23, p. 485]. The objects which are cognized by a person as the space of their own life activity become real. The subjective relation to the objects is performed in comparison (the assessment) of object properties, mediated by the consciousness of other people. The evaluation of an object significance and the degree of its risk happens due to this. This evaluation consists of its nature understanding (basic relation aspect) and the 
understanding of his relation with the specific conditions of life activity (social and situational aspect). Both aspects are interrelated, and are resulted in an object image form. An imaginative cognition of reality requires a special form of relation to its objects - not just to techniques and technologies, but also to emerging risks. In general, research shows that people tend to calculate the risks, the information about which is more accessible; an easily imagined risk is usually overestimated, the threats that are in close proximity, i.e. among the habitat are the most dangerous ones; rare but memorable types of risk are treated as more serious and dangerous than frequent and general risks, which is obviously conditioned by the effect of addiction to dangers [24, pp. 42-44].

The source of emerging risk knowledge is the study of objective reality i.e. the conditions of the habitat. Due to the knowledge about the condition of man-made, natural, informational, social and cultural environment, the understanding of subenvironmental loci features and the resulting dangers and threats, a more or less adequate subjective view appears about them as the objects of reality. But the reality objects are realized by different groups as the risks of life and the object of regulation.

One of the significant contradictions of the modern risk society is an objective and a natural contradiction between progress and its negative impact on the environment, between new opportunities and the growing dangers and threats. When ineffective policy takes place contradictions are not solved timely, and accumulate, leading to the reproduction of risk. Thus, the environmental balance between the living conditions of individuals and groups and their needs and expectations is disrupted, which requires appropriate regulatory interventions.

With regard to the issue of risk regulation social regulation involves a purposeful action, carried out by the means of direct management influence or selfregulation, as the consequence of living condition conscious change, the creation of the necessary incentives or other means of indirect effects. Their common goal is the reduction of threats appearing in subenvironmental loci.

A special role in the risk regulation mechanism belongs to reflection - the «theoretical understanding of one's activity reasons» [25, p. 239], and the ability to respond to changes in a risk habitat. The interaction of institutional structures and selforganized groups during risk reflection provides a more complete understanding of risk and its manifestations in specific subenvironmental loci. Due to the critical analysis of the environment state and its risk, the risk management measures are explained. The system of formal and informal rules and procedures aimed to monitor the risk processes is developed at institutional level, and an adequate response as the basis for the selection of optimal behavior strategies within risk terms is developed at individual and group level.

However, in modern society, social regulation is not based mainly on enforcement but on informationcommunicative interaction of subjects. Accordingly, the redistribution of the priorities from a focused impact takes place within the control system of social organization as an external factor, to selforganization, as the result of internal self-reflection. Therefore, the subjects of regulation are not only the institutional structures that organize regulatory strategies and provide them a systemic nature, but also individuals and groups as self-organized actors who are aware of their own needs, interests and values. In the course of their interaction with each other and with social institutions the most common criteria for risk assessment are developed and its regulation aims are specified in the environment. Together they allow you to determine the extent of an acceptable risk, the basic steps for its optimization and to expect an effect.

The study show [26], that even an active riskreflection of regulatory process entities entails, as a rule, the positive evaluations of risk management capabilities and expands the space of social reality. Not only new risks, but also the ability of their control becomes real. Similarly, the ideas, aspirations and the actions of other participants of the regulatory process (institutional or public organizations) are valued. Positive assessments are resulted in trust, and negative assessments are resulted in distrust towards them. In practice, trust increases the level of certainty and security in the environment and distrust caused by unfulfilled expectations, increases the state of uncertainty and generates the social structure of unsafe environment. The result of new scientific knowledge or rumors about environmental conditions is the replacement of certainty into uncertainty and vice versa. At that a man does not remain a passive observer of changes in the environment, and acts as an active subject and acquires knowledge as after interactions. Therefore, during the transition from certainty to uncertainty, and vice versa, that is, activity related risks change from the credibility to the distrust in respect of habitat objects (technique, technology, government and public institutions, or the decision-makers). Integrating into the social reality, they strengthen or weaken the degree of subenvironmental loci risks and the environment in general.

A number of urgent problems appears in a changing social reality during the process of risk regulation.

Firstly, an order is not so much the result of selforganization but the motion thereto, i.e. not the result 
but the process of self-ordering and self-regeneration based on synergy. Risks and threats regenerating due to uncertainty and non-linearity are not eliminated, but at best are reduced and located in different subenvironmental loci or social groups.

Secondly, the choice of an alternative regulation method is not performed through a determined need, but via an accident, and is the result of conflict, competition and synergy of opposing attractors (the set modes of a system evolution), as well as the activity of subjects. The branching (bifurcation) of possible ways of evolution occurs at the moment of maximum stress.

The choice in a bifurcation point is the consequence of fortuitous circumstances confluence or a conscious activity of subjects. The first model of selection is implemented in a nonlinear developing and little predictable processes of self-organization, when non-linear social fluctuations (random deviations from the mean values), give rise not only to chaos, but also the possibilities of change. The condition of the second selection model is the revealing possibilities of changes when the transition from uncertainty takes place inherent for the bifurcation point, to the certain specific ways of influence on risk environment. In such a situation, the choice becomes the result of possible deviation probability evaluation by participants, providing the self-conscious, calculated risk for a self organization. And the risk becomes the factor of certainty increase and stimulates social activity.

Thirdly, new forms of risk optimization appear in terms of nonlinearity. With the acceleration of social reality and the nonlinear relationship between investments and the result achieved in the process of risk regulation the situational understanding about the rational, i.e., the most optimal in a given situation varies. In the situation of conflict between an urgent need to respond to the risks of the environment by the adoption of concrete measures and their high cost and unpredictability the modern forms of rationalization become useful. The symbolization and performance as the attributes of virtualization are among them.

The symbolic exchange, in contrast to the economic one does not involve the direct exchange of funds, they are replaced by signs. The interaction of people entering into the relations of exchange is virtually unlimited and may include the setting of any objectives, including the most attractive ones, but far from reality, as they are entirely virtual and do not influence the reality itself. «The activity by the means of symbols and signs, which in a certain sense is a virtual activity only, involves only the potential changes in a physical world» [2, p. 145]. The ongoing exchange between the characters, but not between the characters and reality creates the hyperreality under which Jean Baudrillard understands the simulation of anything. Simulative reality is more attractive than the reality that we face in everyday life. For example, a carefully created idea of control strengthening over the quality of food, the use of new medicines, toxic waste disposal, the preservation of cultural monuments, etc have the character of promotional ideas for the development of a positive public opinion about the non-existent or ineffective risk reduction programs. The place of real measures protecting the habitat are occupied by scientific debates, competitions, festivals and spectacular media reportages about them, serving exclusively as the signs and symbols of risk reduction actual policy. Although the relation with reality in the process of symbolization and imitation becomes broken [5, pp. 565-568], it should be noted, that such strategies are quite functional in terms of tension reduction and the statement of some level of certainty. Its retention depends on the search for new vivid forms of presentation.

Thus, the expected achievements in the field of risk regulation are transformed in a bright show called «risk management», develop positive attitudes in the form of hope, people's willingness to trust the propaganda or hope for the best. However, at the exposure of fakes and its comparison to reality, unfulfilled hopes do not lead to frustration by the actions of the institutional structures immediately, and they achieve a symbolic form for some time («if only there is no war») or is replaced by other existential manifestations - patience («I've had worse»), fear («let it be so, the things of others are worse»).

Post-modern forms of rationalization act as the factors of people social life dynamic organization, an active role of which belongs to themselves. For example, organizations, movements, associations, which take over the functions of environmental protection, historical heritage, etc. are created with the help of a state support. Their actions become symbolic ones. And they exist in the form of signs - the attributes of civil society, public or political pressure groups with their offices, elected to the authorities, but without a real impact on the process of risk regulation and only pretending. Such theatrical activities (like the The Mickey Mouse Company, described by Ilf and Petrov), in practice becomes the way of a purposeful regulation of risk in terms of non-equilibrium environment and constantly increasing threats. Thus, the risk regulation funds become the part of the sign system, and the process of its regulation becomes the act of manipulation with signs.

Implementing simulative practices, social institutions are adapted to the management in a nonlinear social dynamics, and the individuals and groups, simulating real activity, giving it a playing, not a real character, gradually adapt to the risk environment. 
Through self-reflection successful gaming practices are institutionalized gradually, become habitual ones, are included in the value-normative structure of social representations and in everyday interactions, in political, economic, social structures and organizations, ensuring the involvement of individuals and groups to the policy of risk regulation and the access to resources provided for the development and implementation of risk regulation measures. While these strategies are based on the principles of ritualism in his Merton understanding as the replacement of socially significant goals using socially approved means the system of social management in general acquires flexibility and mobility paradoxically. It acquires an opportunity to respond quickly to rising social tensions by old or new simulacra.

An individual self-regulation of risk is associated with the exposure on individuals and groups in order to achieve a status that will be compared to a reference sample. In the case of risk regulation institutional mechanism weakening and the increase of confidence to them self-regulatory mechanisms are enhanced. And, although the regulatory framework is made by social institutions, social behavior is often a direct result of happening by people's perceptions, the attitude towards created situation and is regulated by personal considerations, individual or group experiences, intuitive perceptions about a possible future. Uncertainty and the experience of interaction with the risk medium start a transgressive exit mechanism beyond the virtual boundaries of space and time in order to detect the potential dangers and future threats, realizing the expectations of risk, based on an intuitive foresight and the anticipation of still invisible, but intuitively perceived future changes. According to U. Beck, the concept of risk changes the relationship between time loci: past, present and future. The past loses its power over the present, its place as the cause of the everyday experience and activity is taken by the future - something non-existent, constructed and fictitious. The discussions and debates evolve around fictions, the things which could happen if we did not alter the natural course of development [27, p. 214]. The transgressive mechanism is manifested in the construction of reality with the focus on preventive technologies of interaction in potentially risk-taking habitat.

An important role in the selection performance during the bifurcation point belongs to mentality. It is presented by a deep level of collective and individual consciousness, and including unconscious nonreflected images, behaviors and reactions [28, pp. 616617]. From a sociological point of view, mentality is considered as a historically evolved system of spiritual codes predetermining people's perception of happening things in a certain light, the assessment of events in a certain way, the general vector of their actions. Formed under the influence of natural and social factors embodied in historical memory, mentality manifests itself in the form of phenomena, convictions, beliefs, values, norms of behavior sound estimate $[29 ; 30 ; 31]$. From these positions mentality plays the role of conscious and unconscious risk control.

In the self-regulation of choice mentality role is determined by the fact that, on the one hand, it is directly related to the conditions and way of life of individuals and communities, and on the other hand, it influences the formation of a certain type of «everyday consciousness», which determines the criteria of rationality. Mental representations and sets are reflected in the motivational structure and act as reference samples during the choice of alternative courses of action in terms of risk.

While mental structures that combine unconscious and reflected elements of reality reflection, form a basic aspect of the attitude towards risk environment and the risk as the way of interaction with it, the idea of his connection with the specific conditions of life activity are reflected in the minds of individuals and groups by social-situational risk characteristics. Reflecting in the form of stereotypes, i.e. schematized, simplified images of reality, they dictate the sets on some methods of risk perception, with some risk level in life strategies and daily activities. So, against the acceleration, freedom and openness of modern societies one has a developed sense of fear in respect of unknown, the desire for self-preservation and self-defense, while others have the same developed fear of monotony and boredom, the maniacal search of fun and excitement, the fear of settlement, archaic and cultural backwardness. The need to do everything without losing tempo causes the incorporation of risk in everyday life practice as the sign of modernity and the faster pace of life as the only possible way to adapt to a rapidly changing, escaping reality.

Thus, the development of discussed social regulation issues in risk habitat on an interdisciplinary basis will allow to optimize the process in a changing social reality.

\section{References:}

1. Beck, U. Risk Society. On the way to another modernity. M.: Progress-Tradition, 2000.

2. Ionin L.G. Sociology of culture: the way to new millennium: Textbook for students. - 3rd ed., rev. and add. M.: Logos, 2000. URL: http://sociology2015.ru/index/0-23 (date of appeal: 04/11/2015)

3. Perrow Ch. Normal Accidents: Living with High Risk Technologies. New Brunswick. N.J $\therefore$ Rutgers University Press, 1999. 
4. Perrow Ch. The Next Catastrophe: Reducing our Vulnerabilities to Natural, Industrial, and Terrorist Disasters. Princeton University Press. 2011. VII.

5. Kravchenko S.A. Sociology: the paradigm through the prism of sociological imagination: textbook for high schools. M.: Publishing House «Examen», 2004.

6. Kara-Murza S. Manipulation of consciousness. Moscow, 2000.

7. G. Lubbe. Moving with the time. On the reduction of our stay in the present // Problems of philosophy. 1994. №4.

8. E. Fromm. The anatomy of human destructiveness. M.: AST-LTD, 1998. 2008 .

9. Bauman Z. The changing present. SPb.: Peter,

10. Prigogine I. The End of Certainty. New York: Free Press, 1997.

11. Kravchenko S.A. «Normal anomie»: the contours of the concept // Sociological researches. 2014. №8.

12. Spirkin A.G. The basics of philosophy: Textbook for high schools. M.: Politizdat, 1988 ..

13. Wave processes in social development. Novosibirsk, 1992. 1994.

14. Prigogine, Stengers I. Time, chaos, quantum. M.,

15. Heisenberg V. Physics and philosophy: Part and the whole. M., 1990.

16. Algin A.P. Risk and its role in public life. M., 1989.

17. A.I. Prigogine. Modern sociology of organizations. M., 1995.

18. T.I. Zaslavskaya. Post-socialist transformation process in Russia // Bulletin of the Russian Humanitarian Foundation. 1998. №3.

19. V.V. Lokosov Russian society: transformation of objectives, interests and values. M.: RIC ISPR RAS, 2006.
20. Russia: risks and dangers of the «transition» society / Chief ed. O.N. Yanitsky M.: Institute of sociology, Russian Academy of Sciences, 1998.

21. Y.A. Zubok. The phenomenon of risk in sociology: Youth study experience. M.: Mysl, 2007.

22. Royal Society. Risk: analysis, perception and management. London: Royal Society, 1992.

23. A. Schutz. The formation of concepts and theories in social sciences. From the book «American sociological thought». M., 1994.

24. Wildavsky A. and Drake K. Theories of risk perception: who fears what and why? Daedalus. Special issue on risk. 1990.

25. Kravchenko S.A. Nonlinearity // Sociological Encyclopedic Russian-English dictionary. M.: Astrel -Ast Tranzitkniga, 2004.

26. Chuprov V.I., Zubok Y.A. Social regulation under uncertainty. Methodological features of youth study. M.: Academia, 2008.

27. Beck U. Risk Society Revisited: Theory, Politics and Research Programmes // The Risk Society and Beyond / B. Adam, U. Beck, J. van Loon (eds.). L .: Sage Publication, 2007.

28. Mentality // Sociological encyclopedia: 2 v. V. 1 / The head of scientific project G.U. Semigin; Ch. Ed. V.N. Ivanov. M.: Mysl, 2003.

29. Gurevich A.Y. From the history of mentalities to historical synthesis // The debates about the main thing: discussions about the present and the future of history around the French school of «Annals». M., 1993.

30. O.G. Usenko. To the definition of «mentality» concept // Russian history: the problems of mentality. M., 1994.

31. Minyushev F.I. Sociology of culture. M: Academic Project, 2004. 